\title{
Mesospheric CO above Troll station, Antarctica observed by a ground based microwave radiometer
}

\author{
C. Straub ${ }^{1, *}$, P. J. Espy ${ }^{1,2}$, R. E. Hibbins ${ }^{1,2}$, and D. A. Newnham ${ }^{3}$ \\ ${ }^{1}$ Norwegian University of Science and Technology (NTNU), Trondheim, Norway \\ ${ }^{2}$ Birkeland Centre for Space Science, Bergen, Norway \\ ${ }^{3}$ British Antarctic Survey, Cambridge, UK \\ *now at: Institute for Applied Physics, University of Bern, Bern, Switzerland \\ Correspondence to: C. Straub (corinne.straub@ntnu.no)
}

Received: 14 November 2012 - Published in Earth Syst. Sci. Data Discuss.: 10 January 2013

Revised: 10 May 2013 - Accepted: 13 May 2013 - Published: 10 June 2013

\begin{abstract}
This paper presents mesospheric carbon monoxide (CO) data acquired by the ground-based microwave radiometer of the British Antarctic Survey (BAS radiometer) stationed at Troll station in Antarctica $\left(72^{\circ} \mathrm{S}, 2.5^{\circ} \mathrm{E}, 1270 \mathrm{~m}\right.$ a.s.1.). The dataset covers the period from February 2008 to January 2010 , however, due to very low CO concentrations below approximately $80 \mathrm{~km}$ altitude in summer, profiles are only presented during the Antarctic winter. $\mathrm{CO}$ is measured for approximately $2 \mathrm{~h}$ each day and profiles are retrieved approximately every half hour. The retrieved profiles, covering the pressure range from 1 to $0.01 \mathrm{hPa}$ (approximately 48 to $80 \mathrm{~km}$ ), are compared to measurements from Microwave Limb Sounder on the Aura satellite (Aura/MLS) and Whole Atmosphere Community Climate Model with Specified Dynamics (SD-WACCM). This intercomparison reveals a low bias of 0.5 to $1 \mathrm{ppmv}$ at $0.1 \mathrm{hPa}$ (approximately $64 \mathrm{~km}$ ) and 2.5 to $3.5 \mathrm{ppmv}$ at $0.01 \mathrm{hPa}$ (approximately $80 \mathrm{~km}$ ) of the BAS microwave radiometer compared to both reference datasets. One explanation for this low bias could be the known high bias of MLS which is on the same order of magnitude. The ground based radiometer shows high and significant correlation (coefficients higher than 0.9/0.7 compared to MLS/SD-WACCM) at all altitudes compared with both reference datasets.
\end{abstract}

The dataset can be accessed under http://dx.doi.org/10/mhq.

\section{Introduction}

From the stratosphere to the upper mesosphere carbon monoxide $(\mathrm{CO})$ mixing ratios increase by more than one order of magnitude. The large reservoir of mesospheric and lower thermospheric $(75-100 \mathrm{~km}) \mathrm{CO}$ is mainly produced by ultra-violet photodissociation of carbon dioxide $\left(\mathrm{CO}_{2}\right)$. The photochemical loss of CO in the stratosphere and mesosphere is governed primarily by the oxidation reaction with hydroxyl (OH) to form $\mathrm{CO}_{2}$ (Minschwaner et al., 2010). During the polar night, the lifetime of mesospheric $\mathrm{CO}$ is longer than 30 days (Minschwaner et al., 2010), which, together with its strong vertical gradient in the mesosphere, makes it a valuable tracer for dynamics. The strong descent of air during winter in the polar middle atmosphere transports $\mathrm{CO}$-rich air down towards the stratosphere, leading to a downward tilt of the $\mathrm{CO}$ isopleth towards the winter pole. In the past, $\mathrm{CO}$ measurements have been used to infer rates of polar descent (e.g., Allen et al., 2000; Forkman et al., 2005; Lee et al., 2011) as well as to study horizontal transport during strong dynamical events such as stratospheric sudden warmings (e.g., Manney et al., 2009).

Remote sensing observations of $\mathrm{CO}$ in the microwave region using the rotational transitions at $115 \mathrm{GHz}$ and $230 \mathrm{GHz}$ have been performed since 1976 (Waters et al., 1976). Until the early 2000 s such measurements have been mostly on a campaign basis focusing on seasonal variations at mid-latitudes (e.g., Clancy et al., 1984; Bevilacqua et al., 1985; Aellig et al., 1995). Recently, however, three groundbased radiometers measuring $\mathrm{CO}$ have been installed in the 
Northern Hemisphere at high latitudes and are taking measurements on a regular basis: the radiometer in Onsala, Sweden described in Forkman et al. (2012) from 2002 to 2008 (continuation planned); the radiometer in Kiruna, Sweden described in Hoffmann et al. (2011) since 2008; and the instrument in Thule, Greenland described in Biagio et al. (2010), taking measurements every January to March since 2009. The CO measurements of the instruments in Kiruna and Onsala have been compared to data from Microwave Limb Sounder on the Aura satellite (Aura/MLS) and model output from Whole Atmosphere Community Climate Model with Specified Dynamics (SD-WACCM) and to data of several satellites (Hoffmann et al., 2012; Forkman et al., 2012).

This paper describes ground-based measurements of mesospheric $\mathrm{CO}$ taken from Antarctica and compares them to data from Aura/MLS and output of SD-WACCM. The profiles presented are stored in the database of the British Antarctic Survey (http://dx.doi.org/10/mhq).

\section{Measurement}

The ground-based microwave radiometer of the British Antarctic Survey (BAS) measures spectra in the region of the rotational transitions centered at $250.796 \mathrm{GHz}$ (nitric oxide, NO), $249.79 \mathrm{GHz}$ and $249.96 \mathrm{GHz}$ (ozone, $\mathrm{O}_{3}$ ), and $230.538 \mathrm{GHz}$ (carbon monoxide, $\mathrm{CO}$ ). The instrument has been designed in order to study the effects of energetic particle precipitation on the middle and upper atmosphere, using the $\mathrm{NO}$ and $\mathrm{O}_{3}$ data (e.g., Newnham et al., 2011; Daae et al., 2013). This paper focuses on the CO measurements carried out for approximately $2 \mathrm{~h}$ each day in order to study the dynamical context. The data presented have been acquired between February 2008 and January 2010 at Troll station in Antarctica $\left(72^{\circ} \mathrm{S}, 2.5^{\circ} \mathrm{E}, 1270\right.$ a.m.s.l.).

\subsection{Instrument}

The BAS radiometer consists of a highly sensitive, cryogenically cooled radiometer front-end which has been coupled to a spectrometer back-end. It has been designed and manufactured by Radiometer Physics $\mathrm{GmbH}$ in Meckenheim, Germany. The radiometer is a robust system for continuous, semi-autonomous operation in the challenging Antarctic environment that requires a minimum of maintenance and operator intervention. The front-end, schematically shown in Fig. 1, comprises a heterodyne receiver where the incoming radiation is combined with one of two independent local oscillators at 255.6 and $225.6 \mathrm{GHz}$ for the $\mathrm{NO} / \mathrm{O}_{3}$ and $\mathrm{CO}$ observations, respectively, by a superconductor-insulatorsuperconductor (SIS) mixer. The intermediate frequency (IF) signal in the 4-6 GHz range is subsequently amplified by an IF amplifier. Each of the signal bands is analyzed using a moderate-resolution as well as a high-resolution chirp transform spectrometer (CTS) (Hartogh, 1998). For the CO measurements the moderate-resolution CTS was used.

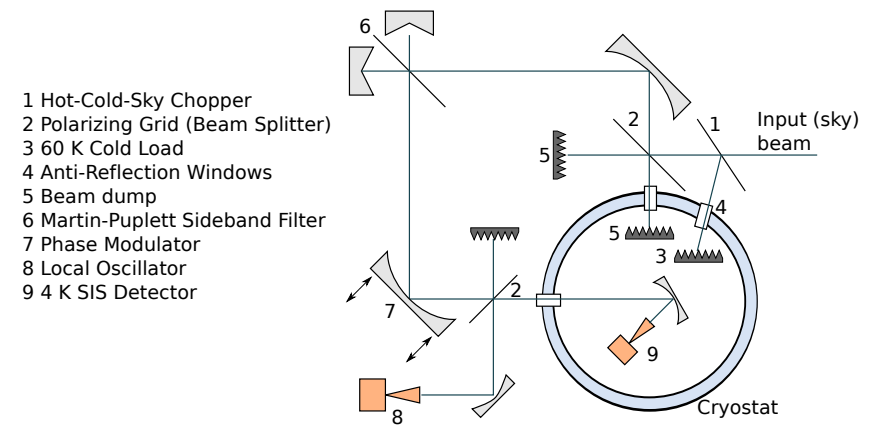

Figure 1. Schematic drawing of the heterodyne receiver of the BAS microwave radiometer.

The instrument has been described in detail in Espy et al. (2006). However, before the operation presented here, there have been two changes to the originally planned setup: (1) the moderate-resolution CTS has a bandwidth of $220 \mathrm{MHz}$ and a resolution of $29 \mathrm{kHz}$ (not $400 \mathrm{MHz}$ and $100 \mathrm{kHz}$ ) and (2) the hot calibration load is at room temperature (approximately $294 \mathrm{~K}$ ) and the cold load at $60 \mathrm{~K}$ (not $60 \mathrm{~K}$ and $4 \mathrm{~K}$ ).

\subsection{Calibration and tropospheric correction}

A three-way mechanical chopper system selects the microwave signal either from the main reflector pointing to the sky at $30^{\circ}$ elevation angle, a $60 \mathrm{~K}$ cold load or an ambienttemperature calibration load mounted on the chopper wheel, and directs it into the main receiver. The sky signal is then calibrated using the switching technique of Dicke and Beringer (1946), as described by Parrish (1994) and references therein. Each calibration cycle takes $27 \mathrm{~s}$ with $8 \mathrm{~s}$ integration time on each target.

For the profile retrieval, we correct each calibrated $\mathrm{CO}$ emission spectrum for attenuation in the troposphere by mainly water vapor. The factor for the tropospheric correction is calculated as described in Forkman et al. (2012).

\subsection{Dataset}

The data presented in this paper are from the BAS radiometer's first period of operation in Antarctica between February 2008 and January 2010 at the Norwegian station Troll. In summer, the mesospheric $\mathrm{CO}$ mixing ratios fall below the instrument's sensitivity level, resulting in negative retrieved volume mixing ratios (VMR) at certain altitudes, and therefore only the data recorded during the months March to October are analyzed. The $\mathrm{CO}$ line is observed for approximately two hours each day. As the change from the local oscillator (LO) used for $\mathrm{NO}$ and $\mathrm{O}_{3}$ measurements to the $\mathrm{LO}$ for the $\mathrm{CO}$ measurements was done manually by an operator, the measurement times vary slightly, e.g., $80 \%$ of the data are recorded between $\pm 2 \mathrm{~h}$ of noon local time, and there are a 98 days without $\mathrm{CO}$ measurements. In order to achieve a 


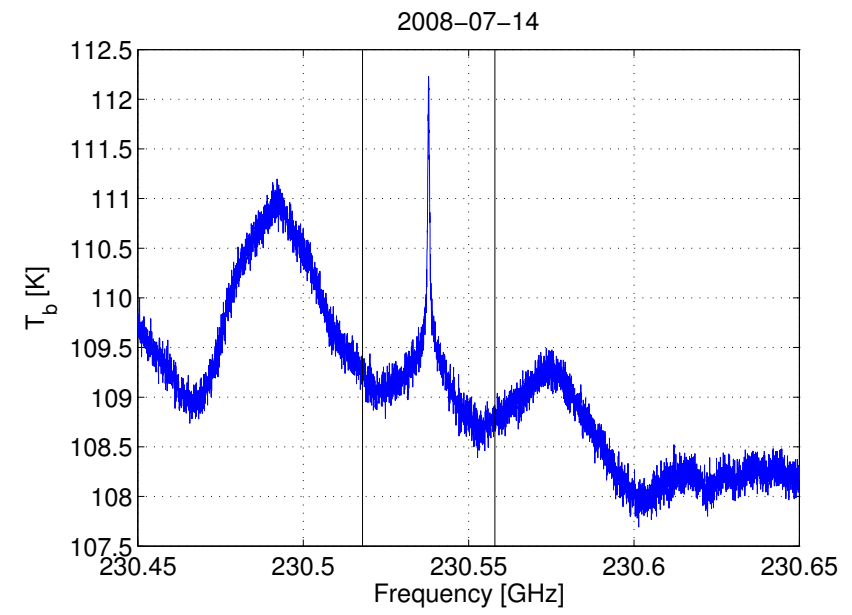

Figure 2. Calibrated spectrum before tropospheric correction. The solid black vertical lines mark the part of the spectrum used for the profile retrieval.

high enough signal to noise ratio for the profile retrieval, several measured spectra are integrated. For this study $80 \mathrm{spec}-$ tra from consecutive calibration cycles are averaged, which under good observing conditions results in a measurement noise of less than $0.15 \mathrm{~K}$ and an integration time of less than $30 \mathrm{~min}$. Spectra with measurement noise higher than $0.25 \mathrm{~K}$ (e.g., due to high tropospheric opacity) are not considered for profile retrieval. During the winters 2008 and 2009 (492 measurement days), the radiometer acquired a total of 1974 integrated spectra over 394 days that are suited for profile retrieval.

A typical integrated spectrum (average of 80 spectra, integration time approximately $24 \mathrm{~min}$ ) is shown in Fig. 2. A large baseline resulting from standing waves in the front-end is visible. However, when just focusing on an area of $40 \mathrm{MHz}$ around the $\mathrm{CO}$ line-center, indicated by the black solid lines, the baseline can be approximated by a low-order polynomial curve fitted to the data as shown in the top panel of Fig. 3.

From February 2008 to the beginning of August the shape of the measured $\mathrm{CO}$ spectra was similar to the one shown in red in Fig. 3. However, on 9 August 2008 a sudden change occurred, and the spectrum acquired shoulders located approximately $\pm 1 \mathrm{MHz}$ on either side of the CO line center (compare blue spectra in Fig. 3). Initial analysis observed these shoulders and their effect on the retrievals (H. C. Pumphrey, personal communication, 2012). The reason for this feature was found to be an instability in the electronic phase-lock control of the $225.6 \mathrm{GHz}$ local oscillator. For the profile retrieval such a feature, being symmetrical around the line center, poses a significant limitation. However, as the feature was stable in amplitude and position over time, we applied an empirical correction, found by systematic trial and error, to the channel response function of the spectrometer during the retrieval process (description in

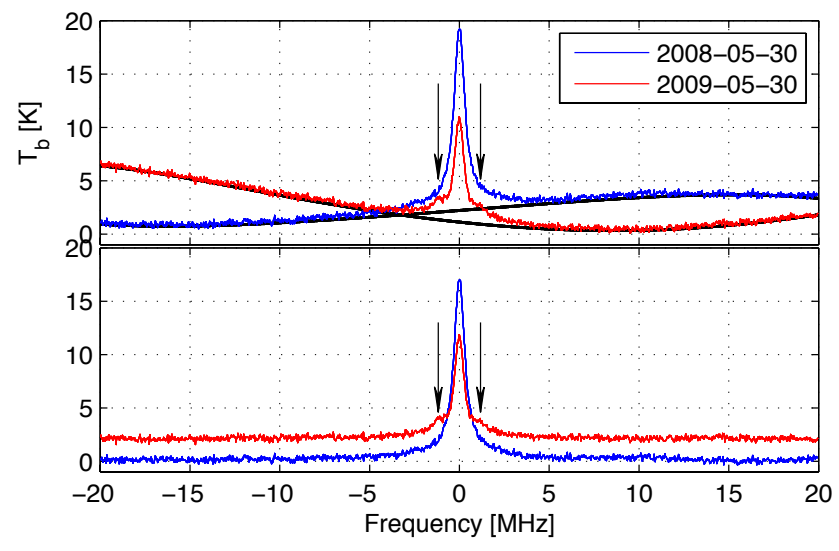

Figure 3. Calibrated $\mathrm{CO}$ spectrum after tropospheric correction as measured before (blue) and after (red) 9 August 2008. The black arrows mark the approximate position of the shoulders the spectrum acquired after 9 August 2008. Top: spectrum before baseline correction and 6th order polynomial fitted to the data. Bottom: spectrum after baseline correction. In the bottom plot, the spectrum of 2009 (red) has been displaced by $2 \mathrm{~K}$ in order to facilitate comparison.

Sect. 3.1). This allowed realistic CO profiles to be retrieved even after the feature appeared.

\section{Retrieval of vertical profiles}

The inversions of the $\mathrm{CO}$ spectra are performed using the optimal estimation method (Rodgers, 2000) implemented in the Qpack software package (v2.0.0) (Eriksson et al., 2005). The forward model is provided by the Atmospheric Radiative Transfer Simulator (ARTS), a modular program simulating atmospheric radiative transfer (Eriksson et al., 2011). For a detailed description of the retrieval of $\mathrm{CO}$ profiles using ARTS and QPack, we refer the reader to Hoffmann et al. (2011) and Forkman et al. (2012). Here we will focus on the discussion of the retrieval setup and the results, including error estimates, of the measurements in Antarctica.

\subsection{Retrieval set-up}

For the inversions the measured spectrum is limited to $40 \mathrm{MHz}$ centered on the $\mathrm{CO}$ line at $230.538 \mathrm{GHz}$. The retrieved quantities are $\mathrm{CO}$ volume mixing ratio, instrumental baseline in the form of a polynomial and a frequency offset. For the baseline fit we choose a polynomial of 6th order as systematic testing showed this to be a good compromise between a stable retrieval without oscillations and fitting too much of the line itself which would lead to a loss of sensitivity at the lowest altitudes. The frequency offset we retrieve is mostly between -40 and $60 \mathrm{kHz}$ and, although there may be some component of Doppler shift due to mesospheric winds, this offset is mainly attributed to instrumental drift.

The line parameters, as input for the forward model, are taken from the HITRAN 2004 spectroscopic database 


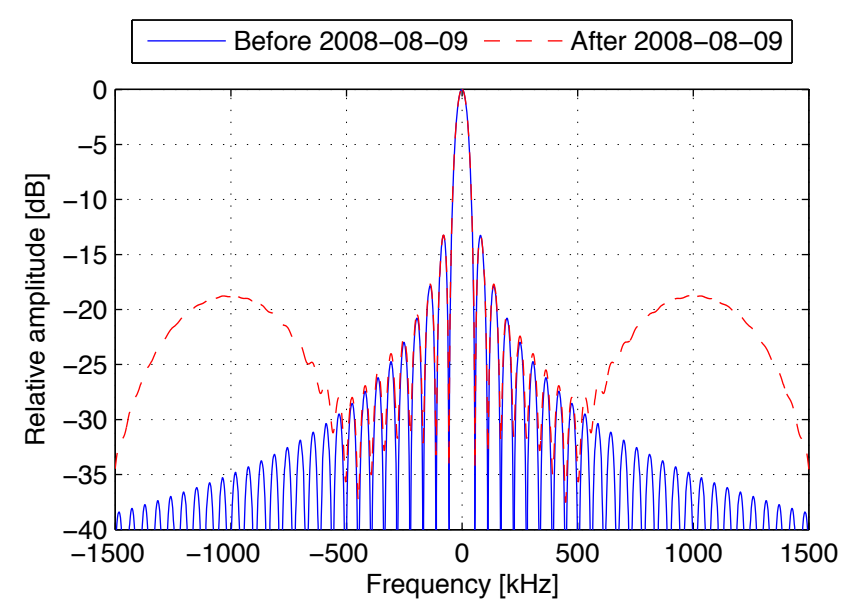

Figure 4. Channel response functions used in the retrieval before and after 9 August 2008.

Rothman et al. (2005). The a priori temperature and CO profiles are constructed from NCAR's Whole Atmosphere Community Climate Model with Specified Dynamics (SDWACCM) data (Lamarque et al., 2012) (description in Sect. 4.2). A monthly mean 20 year climatology is used for the center date of each month, and the values for the days in between are found by linear interpolation. The $\mathrm{CO}$ a priori covariance is held constant at $10 \%$ of the mean a priori profile throughout the year. This value is comparable to the daily standard deviation of $20 \mathrm{yr}$ of SD-WACCM data in the altitude range we expect the BAS radiometer to be sensitive, and somewhat smaller at higher altitudes (above $0.01 \mathrm{hPa}$, $80 \mathrm{~km}$ ). In addition to the diagonal elements, the shape of the a priori covariance matrix is defined as linearly decreasing toward the off-diagonal elements with a correlation length of a quarter of a pressure decade (approximately $4 \mathrm{~km}$ ).

Before 9 August 2008, the channel response function of the spectrometer is approximated with the sinc function (full width at half maximum of $50 \mathrm{kHz}$ ) shown in Fig. 4. After that date an empirical correction in the form of two secondary sinc functions centered at approximately $\pm 1 \mathrm{MHz}$ from the center frequency is applied to the channel response function (also shown in Fig. 4) in order to correct for the feature caused by the local oscillator.

\subsection{Results of the measurements}

The results of two typical measurement of the radiometer are shown in Fig. 5 (top panel before and bottom panel after 9 August 2008). The measured and fitted spectrum, and the difference between the two (residuals) shown in the left panels, indicate that the measured spectrum is fitted accurately and the residuals contain mainly noise contributions (standard deviation of the residuals $\sigma=0.18$ and 0.14 for the 2008 and 2009 spectrum, respectively).
The middle panels indicate that the retrieval has enough freedom in order to estimate a profile clearly different from the a priori even though the a priori covariance used in the inversion is small. The right panels show the Averaging Kernels (AVK) of the inversion, which describe the relationship between the true, a priori and retrieved state of the atmosphere. None of the AVK, even those at higher altitudes, peak above $0.05 \mathrm{hPa}$ (approximately $68 \mathrm{~km}$ ), which is the altitude where Doppler broadening starts to dominate over pressure broadening. This indicates that at this pressure level and above, the retrieval does not provide any altitude profile information, even though it is still sensitive to variations in the CO VMR. The area of the AVK, also shown in the right panels of Fig. 5, indicates that the retrieved profile is determined by the true atmospheric state at altitudes between approximately 1 and $0.01 \mathrm{hPa}$ (area of the AVK >0.8).

The degree of freedom (trace of the AVK matrix) is approximately 2 indicating that 2 independent layers are retrieved in the valid altitude range. This means that the vertical resolution of the retrieval is approximately $15 \mathrm{~km}$.

\subsection{Error characterization}

The estimation of the $1 \sigma$ random measurement error on the radiometer's profiles is based on Rodgers (2000), meaning that the measurement noise on the spectra is propagated through the inversion. The $2 \sigma$ systematic errors are estimated by perturbing the retrieval set-up with the uncertainties of the temperature profile as well as the calibration and the intensity of the $\mathrm{CO}$ line. The temperature profile was perturbed with $5 \mathrm{~K}(1 \sigma$ of $20 \mathrm{yr}$ of monthly SD-WACCM data is between 2.5 and $4 \mathrm{~K}$ at all altitudes) and the intensity of the $\mathrm{CO}$ line with $2 \%$, following the suggestion of Hoffmann et al. (2011). The uncertainty in the radiometer calibration is estimated to have an upper limit of $10 \%$ of the tropospheric correction factor. This estimate accounts for uncertainties in the temperatures of the calibration loads, the observation angle and standing waves on the spectra, as well as for uncertainties in the factor for the tropospheric correction itself.

In addition, we give an upper limit for the systematic error induced by the empirical correction to the channel response function after 9 August 2008. We estimate this error by differencing the profiles inverted with a sinc function with FWHM of $50 \mathrm{kHz}$ (blue in Fig. 4) with those made using the modified sinc function (red in Fig. 4).

The results of the error calculations are displayed in Fig. 6. The plot indicates that the uncertainty induced by the modified channel response function after 9 August 2008 dominates the systematic error and therefore we conclude that the shape of the channel response function is a critical parameter for the absolute values of the retrieved profile. In laboratory experiments the channel response of the CTS was characterized $0.5 \mathrm{MHz}$ about the line center. However, this frequency range proved to not be sufficient for the back end characterization in the profile retrieval and therefore a sinc function 

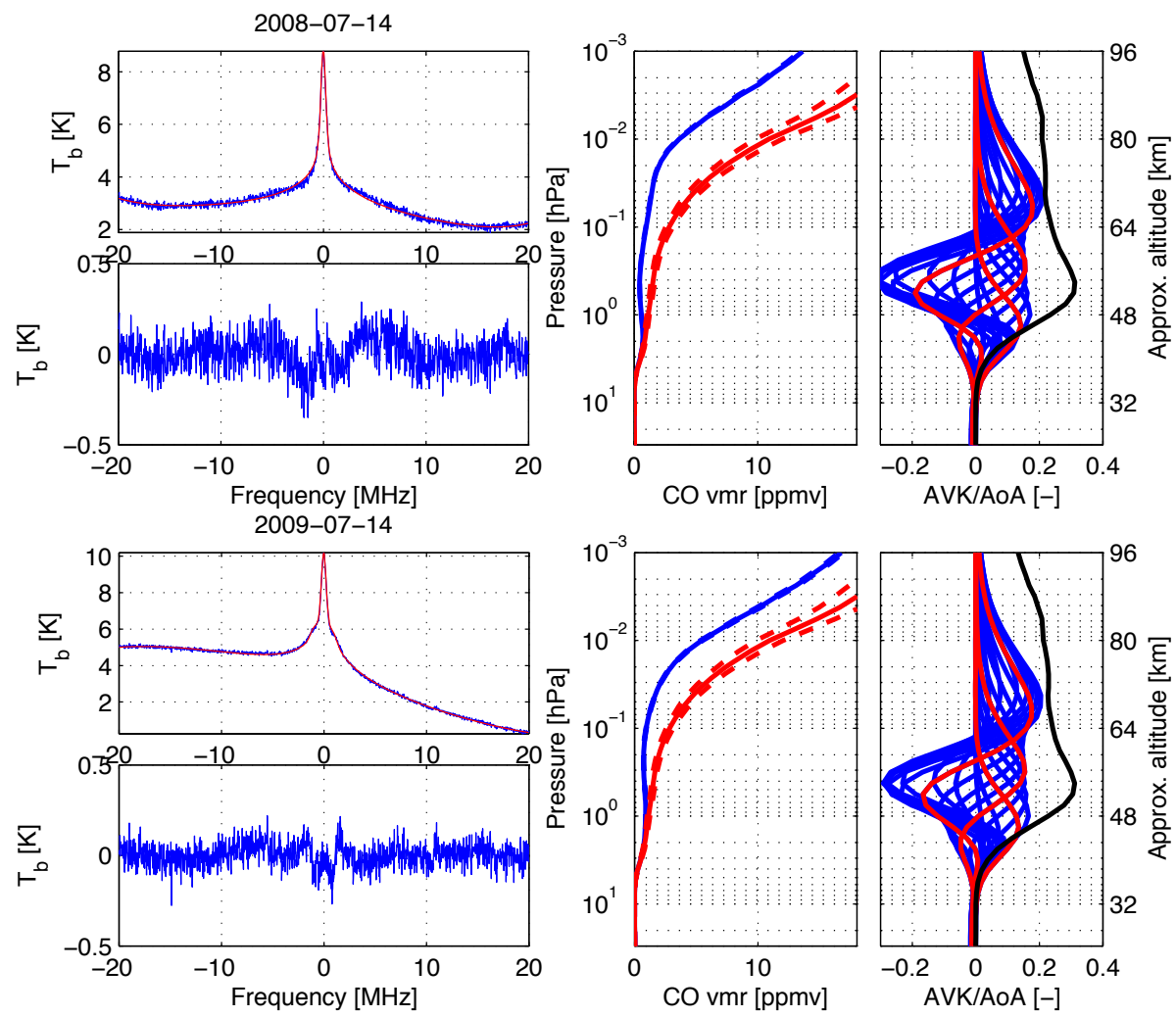

Figure 5. Retrieval before (top) and after (bottom) 9 August 2008. Left top: calibrated spectrum after tropospheric correction (blue) and fit found using optimal estimation (red). Bottom left: residuals. Middle: estimated atmospheric profile with measurement error (blue) and a priori with covariance (red). Right: AVK (red - 1, 0.1 and $0.01 \mathrm{hPa}$ ) and area of the AVK divided by 4 (measurement response).

was used as an approximation. This might introduce an additional systematic error which we have not been able to characterize here.

\section{Comparison to Aura/MLS and SD-WACCM}

In this section we present a comparison between the $\mathrm{CO}$ VMRs retrieved from the measurements of the BAS radiometer, the values found by the Microwave Limb Sounder on the Aura satellite (Aura/MLS) and modeled values from the Whole Atmosphere Community Climate Model with Specified Dynamics (SD-WACCM).

\subsection{Aura/MLS}

The Aura satellite is in a Sun-synchronous orbit passing through two local times at latitudes up to $82.5^{\circ}$. The MLS instrument is described in Waters et al. (2006); a validation of the CO measurements (version 2.2) is given in Pumphrey et al. (2007); and an overview of the version 3.3 retrievals is given in Livesey et al. (2011). We use the MLS version 3.3 $\mathrm{CO}$ product which covers the pressure range 215 to $0.005 \mathrm{hPa}$ with a vertical resolution of approximately $6 \mathrm{~km}$ throughout the mesosphere. The single profile precision $(1 \sigma$ random er- ror estimated from the level 2 algorithms) degrades throughout the mesosphere from $0.15 \mathrm{ppmv}$ at $1 \mathrm{hPa}$ to $4 \mathrm{ppmv}$ at $0.01 \mathrm{hPa}$, and the validation against ACE/FTS suggests that MLS has a positive bias between 30 and $50 \%$ throughout the mesosphere (Waters et al., 2006; Livesey et al., 2011).

For the intercomparison we use MLS profiles within a range of $\pm 1^{\circ}$ in latitude and $\pm 5^{\circ}$ in longitude from the Troll station.

\subsection{SD-WACCM}

WACCM is a comprehensive chemistry-climate model using a free-running dynamical core that is adopted from the NCAR Community Atmosphere Model (CAM). Its chemistry module is an extension of version 3 of the Model of OZone And Related Tracers (MOZART3) (e.g., Kinnison et al., 2007). The gravity wave parameterization in WACCM (Richter et al., 2010) simulates effects of unresolved gravity wave sources such as topography, convection (mostly in low latitudes), and frontal dynamics (middle and high latitudes). The parameterization also gives a coefficient for vertical eddy diffusion that affects heating and the mixing ratios of trace species. For the specified dynamics (SD) runs described in Lamarque et al. (2012), wind and temperature fields are nudged at each model time step using the Goddard 

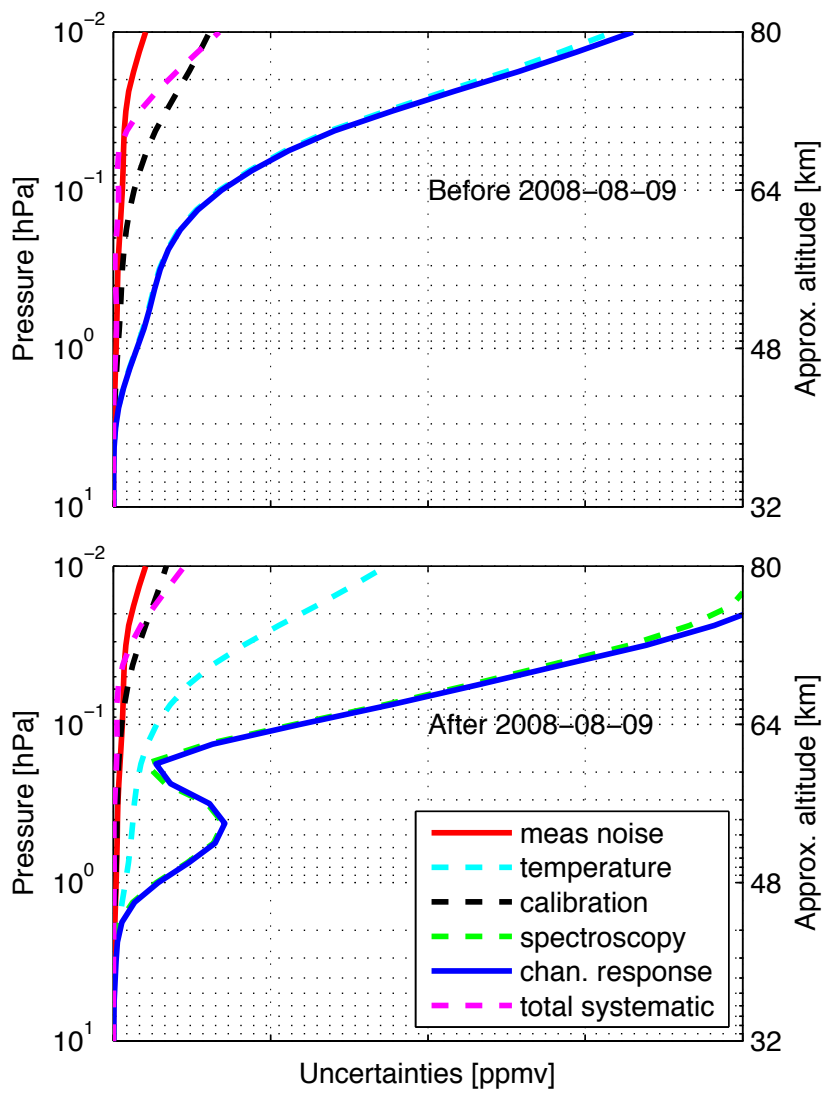

Figure 6. Estimated uncertainties for the BAS radiometer. The uncertainty caused by the measurement noise $(1 \sigma$, red) is regarded as random while the systematic error $(2 \sigma)$ is determined by perturbing the temperature profile (magenta dashed), calibration (cyan dashed), spectroscopic parameters (blue dashed) and the channel response function (green dashed) with the respective uncertainties. Top: before 9 August 2008, Bottom: after 9 August 2008.

Earth Observing System 5 (GEOS-5) analysis. The specified dynamics option allows the use of WACCM as a chemical transport model which facilitates the comparisons with observations of trace chemical species as the state of the real atmosphere at a given time is reproduced. The SD-WACCM run used for this intercomparison is nudged with $1 \%$ of the GEOS-5 meteorological fields below $60 \mathrm{~km}$ (e.g., temperature, zonal and meridional winds, and surface pressure) every $30 \mathrm{~min}$. Latitude and longitude resolution for these WACCM runs is $1.9^{\circ} \times 2.5^{\circ}$ and there are 88 pressure levels from the surface to $150 \mathrm{~km}$ altitude. For the intercomparison we use the WACCM midnight profile at the grid point $\left(72.95^{\circ} \mathrm{S}\right.$, $\left.2.5^{\circ} \mathrm{E}\right)$ closest to the Troll station.

\subsection{Results and discussion}

A set of coincident profiles is generated by first searching for all the profiles from the BAS radiometer within one day. Then we take the mean of the time of all profiles found on a certain day, and search for all MLS (WACCM) profiles within $12 \mathrm{~h}$ before and after that time. From this set of profiles we use the MLS (WACCM) and BAS radiometer profile closest in time. This strategy results in 312 (342) coincident profiles that are not interdependent. We henceforth refer to the coincident profiles of MLS and WACCM as the reference profiles.

As MLS and SD-WACCM both have a better altitude resolution than the radiometer, the reference profiles are convolved with the AVKs from the radiometer data inversion.

\subsubsection{Temporal variations}

The three different time series of coincident profiles on two pressure levels in the mesosphere $(0.3$ and $0.03 \mathrm{hPa}$, approximately 56 and $72 \mathrm{~km}$ ) are shown in Fig. 7 indicating good general agreement. From this figure it is clearly visible that the MLS (SD-WACCM) and BAS radiometer data are correlated on a timescale in the order of months. The correlation coefficients are larger than 0.9 (MLS) and 0.7 (SD-WACCM) at all altitudes and statistically significant at the $99 \%$ confidence level. In order to quantify the correlation on a shorter timescale, we calculate correlation coefficients with variations longer than 20 days removed (high-pass filter with a cut-off at 20 days). This results in correlation coefficients larger than 0.6 (significant at greater than the $99 \%$ confidence level) between MLS and the BAS radiometer while between SD-WACCM and the BAS radiometer no significant correlation is found. The relatively high correlation of the short-term variations between MLS and the BAS radiometer indicate that the short-term variability is not only due to noise in one or both instruments but clearly driven by atmospheric variations. These short-term atmospheric variations above Antarctica seem to be not well represented in SDWACCM. Hoffmann et al. (2012) did a similar analysis for their ground based radiometer in Kiruna and found a similar correlation between the short-term variations in MLS and radiometer data. Similarly, they find a small, albeit significant, correlation on the order of 0.4 for the short-term variations between SD-WACCM and the ground-based radiometer.

\subsubsection{Intercomparison of profiles}

The intercomparison strategy used closely follows Stiller et al. (2012) and Tschanz et al. (2013); the results are displayed in Figs. 8. The plots to the left of Fig. 8 show the mean coincident profile for each of the three datasets, before 9 August 2008 in the top panel and after in the bottom panel. The comparison indicates that the CO VMRs from the BAS radiometer have a low bias at all altitudes compared to the two reference profiles, while the reference profiles are in good agreement.

The middle panel displays the bias and standard error of the datasets together with the estimated systematic error of the BAS radiometer. The systematic error on the reference 

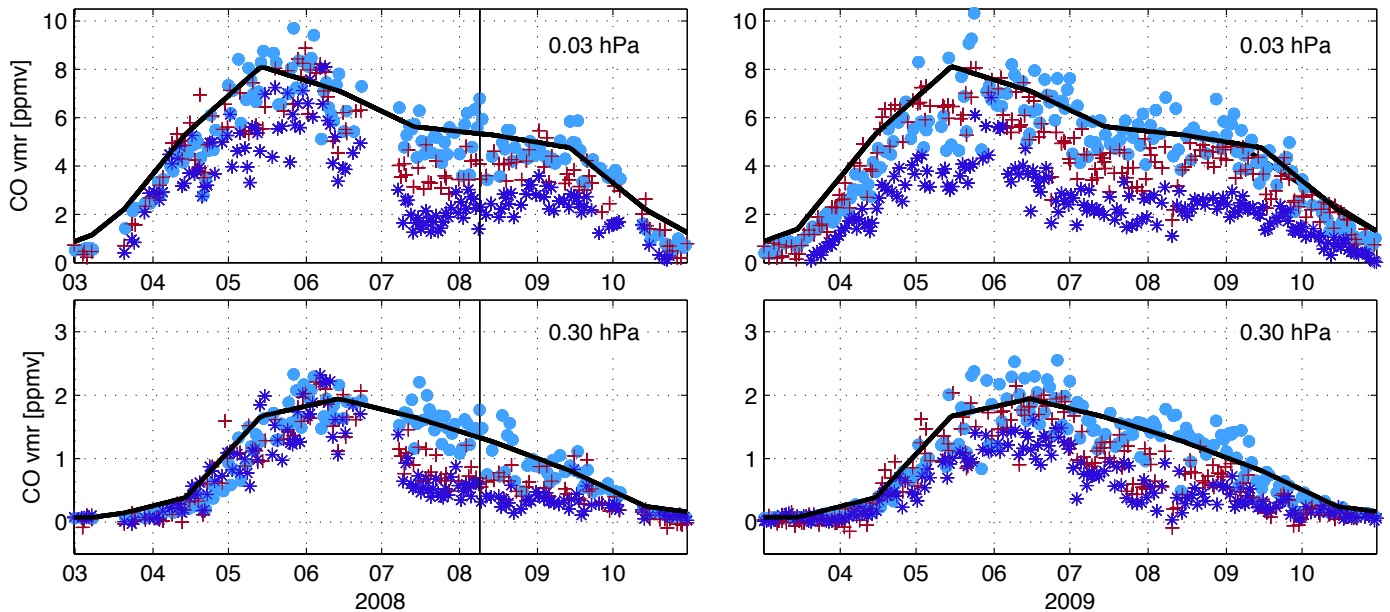

Figure 7. Time series of the BAS radiometer data (blue *) at two pressure levels (top: $0.03 \mathrm{hPa}$, bottom: $0.3 \mathrm{hPa}$ ) for the Antarctic winters 2008 and 2009 together with MLS (red +) and SD-WACCM data above Troll station (light blue $\bullet$ ). The black line indicates the a priori VMR used in the BAS radiometers retrieval.

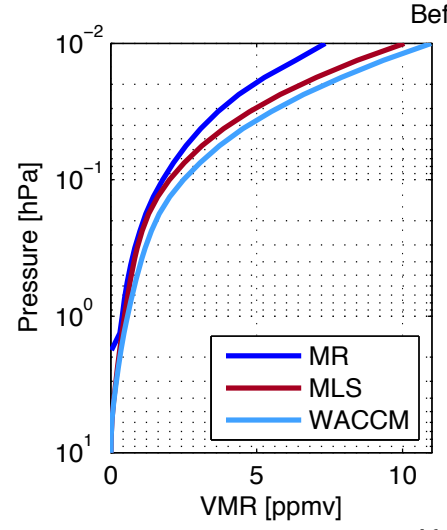

Before 2008-08-09, 84/112 profiles
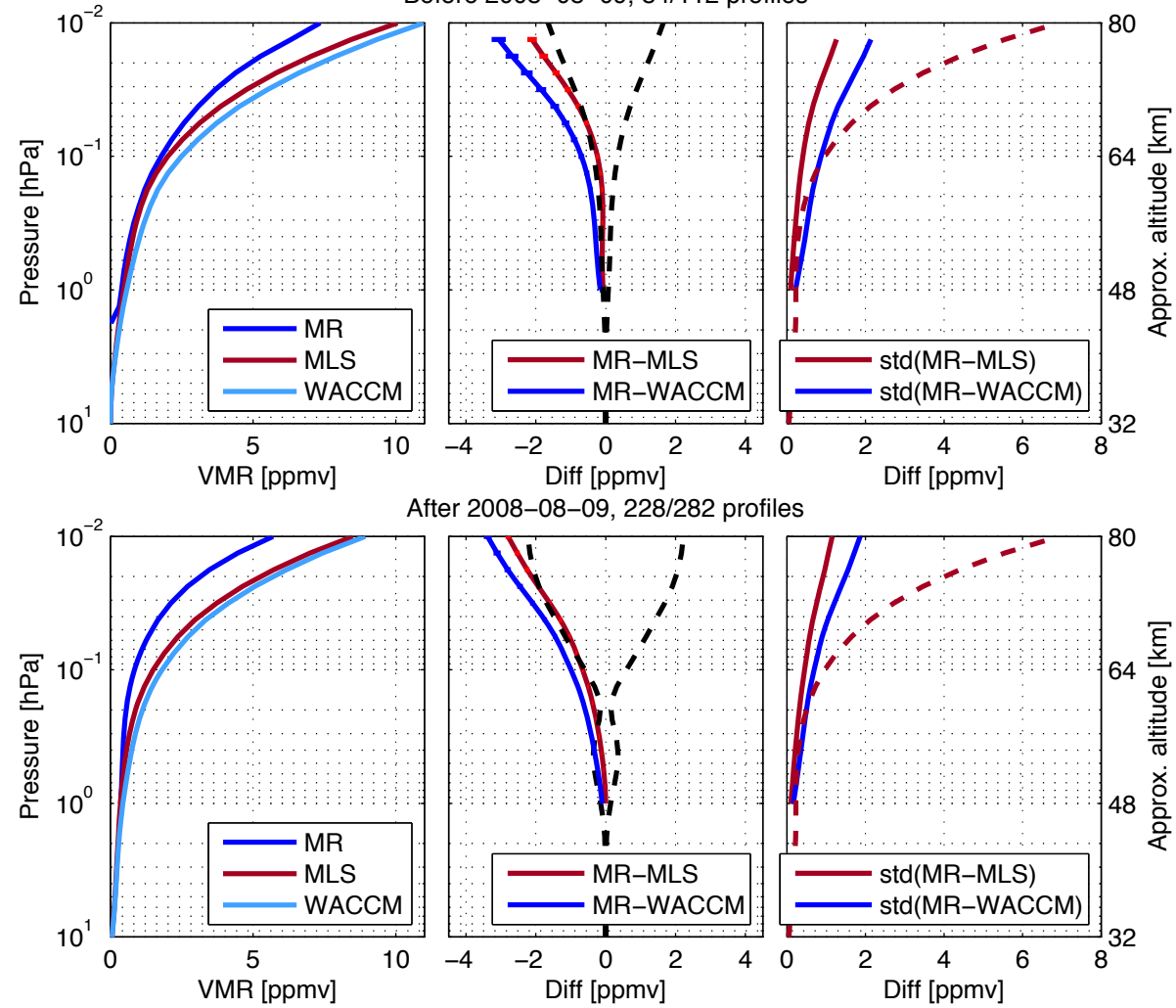

After 2008-08-09, 228/282 profiles
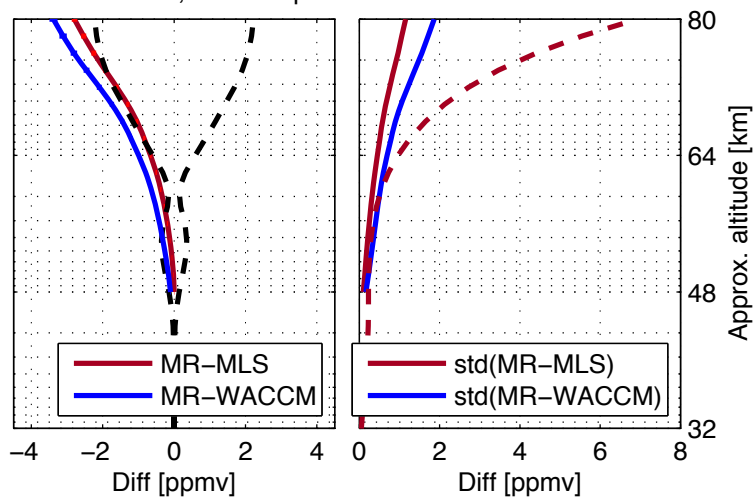

Figure 8. Intercomparison between BAS microwave radiometer (MR) and MLS (red) or SD-WACCM (light blue), respectively. Left: mean coincident profiles of BAS radiometer (blue), MLS and SD-WACCM. Middle: bias with standard error and estimated systematic error of the BAS radiometer (black dashed). Right: standard deviation of difference and combined random errors of MLS and the BAS radiometer (red dashed). 
profiles is assumed to be negligible. The top plot indicates that before 9 August 2008, the low bias of the BAS radiometer is larger than the estimated systematic error at altitudes above $0.05 \mathrm{hPa}$ compared to MLS and at all altitudes compared to SD-WACCM. The bottom plot indicates that after 9 August 2008 this situation has not significantly changed. One explanation for the low bias of the BAS radiometer could be that we underestimate the systematic error of the instrument due to the channel response function not being well characterized. However, when making comparisons with MLS CO data we need to keep in mind that MLS CO profiles have a known high bias of 30-50\% compared to ACE-FTS (Waters et al., 2006; Livesey et al., 2011) (corresponding to approximately $2-3 \mathrm{ppmv}$ at $0.01 \mathrm{hPa}$ and $0.3-0.5 \mathrm{ppmv}$ at $0.1 \mathrm{hPa}$ ) in the mesosphere, which could be the explanation for the apparent low bias of the BAS radiometer. Unfortunately, the BAS radiometer data cannot be directly compared to ACEFTS due to a lack of coincident profiles. The SD-WACCM profiles have previously been found to be in good agreement with MLS by Hoffmann et al. (2012).

The right panel of Fig. 8 displays the standard deviation of the difference between the profiles together with the combined random errors of the BAS radiometer and MLS. The estimated random error is larger than the standard deviation of the difference hinting towards an overestimation of the random error. The combined estimated uncertainty mainly represents MLS, as the satellite's estimated random error is clearly larger than that of the BAS radiometer. There are no uncertainties provided along with the SD-WACCM profiles.

Previous studies by Hoffmann et al. (2012); Forkman et al. (2012) have compared CO measurements from ground-based radiometers in Kiruna and Onsala, respectively. In agreement with our study, both of these studies find a negative bias of the ground-based radiometers compared to MLS at altitudes below $60 \mathrm{~km}$. However, in contrast to out study both of the radiometers described in Hoffmann et al. (2012) and Forkman et al. (2012) show a stronger increase of CO VMR above $60 \mathrm{~km}$ compared to MLS which leads to a positive bias of the ground-based instruments compared to the satellite.

\section{Conclusions and outlook}

This paper presents mesospheric $\mathrm{CO}$ measurements between February 2008 and January 2010 acquired by a ground based microwave radiometer stationed at the Troll station, Antarctica. The instrument, measuring $\mathrm{CO}$ for approximately $2 \mathrm{~h}$ per day, acquired 1974 spectra on 394 days (out of 492 possible days) during the Antarctic winter months of MarchOctober of 2008 and 2009. Under good observing conditions, we retrieve a profile covering the pressure range 1 to $0.01 \mathrm{hPa}$ every $30 \mathrm{~min}$.

The retrieved profiles have been compared to measurements of Aura/MLS and model runs of SD-WACCM. This intercomparison indicates a low bias of 0.5 to $1 \mathrm{ppmv}$ at
$0.1 \mathrm{hPa}$ and 2.5 to $3.5 \mathrm{ppmv}$ at $0.01 \mathrm{hPa}$ of the BAS radiometer compared to both reference datasets. MLS has a known high bias of the same order of magnitude in the mesosphere which could be the explanation for that intercomparison result. The high and significant correlation of the time series at all altitudes indicates that the BAS radiometer monitors realistic short- and long-term variations of mesospheric CO.

In Spring 2010, the BAS radiometer has been brought back to Europe for maintenance. After an upgrade to allow for fully automated switching between $\mathrm{NO} / \mathrm{O}_{3}$ and $\mathrm{CO}$ the BAS radiometer was taken back to Antarctica during the austral summer of 2012/2013 in order to continue measurements of the polar middle atmosphere.

Acknowledgements. We thank Anne K. Smith for providing the SD-WACCM data used in this paper and Patrick Erikson and Ole Martin Christensen for helpfull discussions on the data retrieval. In addition, we thank Mark Clilverd at BAS, Kim Holmen at the Norwegian Polar Institute (NPI) and Paul Hartogh at Max Planck Institute (MPI, Germany) for their support of the BAS microwave radiometer. We also thank the Troll station overwintering engineers Atle Markussen, Asbjorn Djupdal, and Tore Dahl as well as David Maxfield and Paul Breen at BAS for their help. Furthermore, we thank Peter Kirsch for help with the issuing of the DOI. The work at NTNU has been funded by the Norwegian Polar Institute Antarctic Program under the grant "Observations of carbon monoxide and ozone in the Antarctic and Arctic: Implications for the Inter-hemispheric coupling of vertical motions". The BAS microwave radiometer project is funded in part by the Natural Environment Research Council (UK).

Edited by: D. Carlson

\section{References}

Aellig, C. P., Kämpfer, N., and Hauchecorne, A.: Variability of mesospheric $\mathrm{CO}$ in the fall and winter as observed with groundbased microwave radiometry at $115 \mathrm{GHz}$, J. Geophys. Res., 100, 14125-14130, 1995.

Allen, D. R., Stanford, J. L., Nakamura, N., López-Valverde, M. A., López-Puertas, M., Taylor, F. W., and Remedios, J. J.: Antarctic polar descent and planetary wave activity observed in ISAMS CO from April to July 1992, Geophys. Res. Lett., 27, 665-668, doi:10.1029/1999GL010888, 2000.

Bevilacqua, R. M., Stark, A. A., and Schwartz, P. R.: The Variability of Carbon Monoxide in the Terrestrial Mesosphere as Determined From Ground-Based Observations of the $\mathbf{J}=1-0$ Emission Line, J. Geophys. Res., 90, 5777-5782, 1985.

Biagio, C. D., Muscari, G., di Sarra, A., de Zafra, R. L., Eriksen, P., Fiocco, G., Fiorucci, I., and Fuà, D.: Evolution of temperature, $\mathrm{O}_{3}, \mathrm{CO}$, and $\mathrm{N}_{2} \mathrm{O}$ profiles during the exceptional 2009 Arctic major stratospheric warming observed by lidar and mm-wave spectroscopy at Thule $\left(76.5^{\circ} \mathrm{N}, 68.8^{\circ} \mathrm{W}\right)$, Greenland, J. Geophys. Res., 115, D24315, doi:10.1029/2010JD014070, 2010.

Clancy, R. T., Muhleman, D. O., and Allen, M.: Seasonal Variability of CO in the Terrestrial Mesosphere, J. Geophys. Res., 89, 96739676, 1984. 
Daae, M., Espy, P. J., Tyssoy, H. N. N., Newnham, D. A., Stadsnes, J., and Soraas, F.: The effect of energetic electron precipitation on middle mesospheric night-time ozone during and after a moderate geomagnetic storm, Geophys. Res. Lett., 39, L21811, doi:10.1029/2012GL053787, 2013.

Dicke, R. H. and Beringer, R.: Microwave radiation from the sun and moon, Astrophys. J., 103, 375-376, 1946.

Eriksson, P., Jiménez, C., and Buehler, S. A.: Qpack, a general tool for instrument simulation and retrieval work, J. Quant. Spectrosc. Ra., 91, 47-64, 2005.

Eriksson, P., Buehler, S. A., Davis, C. P., Emde, C., and Lemke, O.: ARTS, the atmospheric radiative transfer simulator, version 2, J. Quant. Spectrosc. Ra., 112, 1551-1558, 2011.

Espy, P., Hartogh, P., and Holmén, K.: A microwave radiometer for the remote sensing of nitric oxide and ozone in the middle atmosphere, Proceedings of SPIE, 6362, 63 620P, 2006.

Forkman, P., Eriksson, P., Murtagh, D., and Espy, P.: Observing the vertical branch of the mesospheric circulation at latitude $60^{\circ} \mathrm{N}$ using ground-based measurements of $\mathrm{CO}$ and $\mathrm{H}_{2} \mathrm{O}$, J. Geophys. Res., 110, D05107, doi:10.1029/2004JD004916, 2005.

Forkman, P., Christensen, O. M., Eriksson, P., Urban, J., and Funke, B.: Six years of mesospheric $\mathrm{CO}$ estimated from ground-based frequency-switched microwave radiometry at $57^{\circ} \mathrm{N}$ compared with satellite instruments, Atmos. Meas. Tech., 5, 2827-2841, doi:10.5194/amt-5-2827-2012, 2012.

Hartogh, P.: High resolution chirp transform spectrometer for middle atmospheric microwave sounding, in: Satellite Remote Sensing of Clouds and the Atmosphere II, vol. 3220, 115-124, Society of Photographic Instrumentation Engineers, 1998.

Hoffmann, C. G., Raffalski, U., Palm, M., Funke, B., Golchert, S. H. W., Hochschild, G., and Notholt, J.: Observation of stratomesospheric $\mathrm{CO}$ above Kiruna with ground-based microwave radiometry - retrieval and satellite comparison, Atmos. Meas. Tech., 4, 2389-2408, doi:10.5194/amt-4-2389-2011, 2011.

Hoffmann, C. G., Kinnison, D. E., Garcia, R. R., Palm, M., Notholt, J., Raffalski, U., and Hochschild, G.: CO at 40-80 km above Kiruna observed by the ground-based microwave radiometer KIMRA and simulated by the Whole Atmosphere Community Climate Model, Atmos. Chem. Phys., 12, 3261-3271, doi:10.5194/acp-12-3261-2012, 2012.

Kinnison, D. E., Brasseur, G. P., Walters, S., Garcia, R. R., Marsh, D. R., Sassi, F., Harvey, V. L., Randall, C. E., Emmons, L., Lamarque, J. F., Hess, P., Orlando, J. J., Tie, X. X., Randel, W., Pan, L. L., Gettelman, A., Granier, C., Diehl, T., Niemeier, U., and Simmons, A. J.: Sensitivity of chemical tracers to meteorological parameters in the MOZART-3 chemical transport model, J. Geophys. Res., 112, D20302, doi:10.1029/2006JD007879, 2007.

Lamarque, J.-F., Emmons, L. K., Hess, P. G., Kinnison, D. E., Tilmes, S., Vitt, F., Heald, C. L., Holland, E. A., Lauritzen, P. H., Neu, J., Orlando, J. J., Rasch, P. J., and Tyndall, G. K.: CAM-chem: description and evaluation of interactive atmospheric chemistry in the Community Earth System Model, Geosci. Model Dev., 5, 369-411, doi:10.5194/gmd-5-369-2012, 2012.

Lee, J. N., Wu, D. L., Manney, G. L., Schwartz, M. J., Lambert, A., Livesey, N. J., Minschwaner, K. R., Pumphrey, H. C., and Read, W. G.: Aura Microwave Limb Sounder observations of the polar middle atmosphere: Dynamics and transport of $\mathrm{CO}$ and $\mathrm{H}_{2} \mathrm{O}$, J.
Geophys. Res., 116, D05110, doi:10.1029/2010JD014608, 2011. Livesey, N. J., Read, W. G., Froidevaux, L., Lambert, A., Manney, G. L., Pumphrey, H. C., Santee, M. L., Schwartz, M. J., Wang, S., Cofeld, R. E., Cuddy, D. T., Fuller, R. A., Jarnot, R. F., Jiang, J. H., Knosp, B. W., Stek, P. C., Wagner, P. A., and Wu, D. L.: EOS/MLS - Version 3.3 Level 2 data quality and description document, Tech. rep., Jet Propulsion Laboratory, 2011.

Manney, G. L., Harwood, R. S., MacKenzie, I. A., Minschwaner, K., Allen, D. R., Santee, M. L., Walker, K. A., Hegglin, M. I., Lambert, A., Pumphrey, H. C., Bernath, P. F., Boone, C. D., Schwartz, M. J., Livesey, N. J., Daffer, W. H., and Fuller, R. A.: Satellite observations and modeling of transport in the upper troposphere through the lower mesosphere during the 2006 major stratospheric sudden warming, Atmos. Chem. Phys., 9, 47754795, doi:10.5194/acp-9-4775-2009, 2009.

Minschwaner, K., Manney, G. L., Livesey, N. J., Pumphrey, H. C., Pickett, H. M., Froidevaux, L., Lambert, A., Schwartz, M. J., Bernath, P. F., and Walker, K. A.: The photochemistry of carbon monoxide in the stratosphere and mesosphere evaluated from observations by the Microwave Limb Sounder on the Aura satellite, J. Geophys. Res., 115, D13303, doi:10.1029/2009JD012654, 2010.

Newnham, D. A., Espy, P. J., Clilverd, M. A., Rodger, C. J., Seppälä, A., Maxfield, D. J., Hartogh, P., Holmén, K., and Horne, R. B.: Direct observations of nitric oxide produced by energetic electron precipitation into the Antarctic middle atmosphere, Geophys. Res. Lett., 38, L20104, doi:10.1029/2011GL048666, 2011.

Parrish, A.: Millimeter-wave remote sensing of ozone and trace constituents in the stratosphere, Proc. IEEE, 82, 1915-1929, 1994.

Pumphrey, H. C., Filipiak, M. J., Livesey, N. J., Schwartz, M. J., Boone, C., Walker, K. A., Bernath, P., Ricaud, P., Barret, B., Clerbaux, C., Jarnot, R. F., Manney, G. L., and Waters, J. W.: Validation of middle-atmosphere carbon monoxide retrievals from MLS on Aura, J. Geophys. Res., 112, D24S38, doi:10.1029/2007JD008723, 2007.

Richter, J. H., Sassi, F., and Garcia, R. R.: Toward a Physically Based Gravity Wave Source Parameterization in a General Circulation Model, J. Atmos. Sci., 67, 136-156, doi:10.1175/2009JAS3112.1, 2010.

Rodgers, C. D.: Inverse Methodes for Atmospheric Soundings, World Scientific Publishing Co. Pte. Ltd, Singapore, 2000.

Rothman, L. S., Jacquemart, D., Barbe, A., Benner, D. C., Birk, M., Brown, L. R., Carleer, M. R., Chackerian, C., Chance, K., Coudert, L. H., Dana, V., Devi, V. M., Flaud, J.-M., Gamache, R. R., Goldman, A., Hartmann, J.-M., Jucks, K. W., Maki, A. G., Mandin, J.-Y., Massie, S. T., Orphal, J., Perrin, A., Rinsland, C. P., Smith, M. A. H., Tennyson, J., Tolchenov, R. N., Toth, R. A., Auwera, J. V., Varanasi, P., and Wagner, G.: The HITRAN 2004 molecular spectroscopic database, J. Quant. Spectrosc. Ra., 96, 139-204, 2005.

Stiller, G. P., Kiefer, M., Eckert, E., von Clarmann, T., Kellmann, S., García-Comas, M., Funke, B., Leblanc, T., Fetzer, E., Froidevaux, L., Gomez, M., Hall, E., Hurst, D., Jordan, A., Kämpfer, N., Lambert, A., McDermid, I. S., McGee, T., Miloshevich, L., Nedoluha, G., Read, W., Schneider, M., Schwartz, M., Straub, C., Toon, G., Twigg, L. W., Walker, K., and Whiteman, D. N.: Validation of MIPAS IMK/IAA temperature, water vapor, and ozone profiles with MOHAVE-2009 campaign measurements, Atmos. Meas. Tech., 5, 289-320, doi:10.5194/amt-5-289-2012, 2012. 
Tschanz, B., Straub, C., Walker, K., Stiller, G., and Kämpfer, N.: Validation of middle atmospheric water vapor profiles measured by the ground based microwave radiometer MIAWARA-C, accepted, Atmos. Meas. Tech. Discuss., 2013.

Waters, J., Froidevaux, L., Harwood, R., Jarno, R., Pickett, H., Read, W., Siegel, P., Cofield, R., Filipiak, M., Flower, D., Holden, J., Lau, G., Livesey, N., Manney, G., Pumphrey, H., Santee, M., Wu, D., Cuddy, D., Lay, R., Loo, M., Perun, V., Schwartz, M., Stek, P., Thurstans, R., Boyles, M., Chandra, S., Chavez, M., Chen, G.-S., Chudasama, B., Dodge, R., Fuller, R., Girard, M., Jiang, J., Jiang, Y., Knosp, B., LaBelle, R., Lam, J., Lee, K., Miller, D., Oswald, J., Patel, N., Pukala, D., Quintero, O., Scaff, D., Snyder, W., Tope, M., Wagner, P., and Walch, M.: The Earth Observing System Microwave Limb Sounder (EOS MLS) on the Aura satellite, IEEE T. Geosci. Remote, 44, 10751092, 2006.
Waters, J. W., Wilson, W. J., and Shimabokuro, F. I.: Microwave Measurement of Mesospheric Carbon Monoxide, Science, 191, 1174-1175, 1976. 